[Bull. Agr. Chem. Soc. Japan, Vol. 22, No. 1, p. 24 31, 1957]

\title{
Studies on Amino Acids. X
}

\author{
Studies on the Enzymatic Resolution (VIII): Acylase \\ Activity in Eschericheae*
}

\author{
By Ichiro Chibata, Masahiko Kisumi, Shun'ichi Yamada \\ Osaka Research Laboratory, Tanabe Seiyaku Co., Ltd.**
}

Received September 19, 1957

\begin{abstract}
The growth studies of methionine requiring mutant of Escherichia coli disclosed that several acyl methionines were utilized by the mutants. Furthermore, the cell-free extracts of Escherichia coli and Aerobacter aerogenes were found to show almost equal hydrolytic activity towards acyl amino acids.

In order to find the enzymatic properties of the acylase activity, the experiments were carried out with the alcohol-fractionated extracts of the acetone-dried cells of Escherichia coli $K-12$. As a result of the investigation, acylase activity of the preparation from Escherichia coli was found to be lower and also a lesser number of acyl amino acids were hydrolyzed than the mold acylase which had been previously studied by the authors. Activation by cobalt ion and several other observation were also presented.
\end{abstract}

Since several years ago, the authors have been studying on the acylase activity of molds, especially on its practical application for the optical resolution of amino acids ${ }^{1 \sim 6)}$.

Although a number of reports on the studies of acylase activity in animal and fungal sources have appeared, only a few reports have been published concerning the bacterial acylase. So, as a part of the studies aimed at obtaining complete knowledge on acylase activity occurring in various organisms, the authors have performed experiments on the acylase preparation from Escherichiae. The results obtained are presented in this paper.

* Presented at the meeting of the Kansai Division of the Agricultural Chemical Society of Japan, Sakai, July 20, 1957.

* Honjo-Kawasaki-cho, Oyodo-ku, Osaka.

1) S. Yamada, I. Chibata and S. Yamada, J. Pharm. Soc, Jap., 75, 113 (1955).

2) I. Chibata, S. Yamada and S. Yamada, This Bulletin, 20, 174 (1956).

3) I. Chibata, A. Watanabe and S. Yamada, This Bulletin, 21 291 (1957)

4) I. Chibata, A. Watanabe and S. Yamada, This Bulletin, 21, 296 (1957).

5) I. Chibata, T. Ishikawa and S. Yamada, This Bulletin, 21, 300 (1957).

6) I. Chibata, T. Ishikawa and S. Yamada, This Bulletin, 21, 305 (1957).
On the acylase activity. that is, hydrolytic activity towards acyl amino acids, Imaizumi7) reported that hippuric acid could not be hydrolized by the extracts of Escherichia coli but formyl-, acetyl-glycins and chloroacetylL-phenylalanine were hydrolized, although that last mentioned only slightly. Tomoda, Saito $^{8)}$ and Kameda, Toyoura9) also confirmed that the dried preparation and cell suspension of Escherichia coli could not hydrolize hippuric acid and benzoyl-DL-phenylalanine. During the course of authors' study, Vogel and Bonner10) have reported on the acetylornithinase of Escherichia coli and have found that the acetylornithiase could deacetylate not only acetylornithine but also acetylmethionine. Although a number of other acyl amino acids had been tested, they were not susceptible to the preparation.

\footnotetext{
7) M. Imaizumi, J. Biochem., 27, 199 (1938).

8) S. Tomoda and H. Saito, Toboku J. Expel. Med., 39, 211 (1940)

9) Y. Kamada and E. Toyoura, J. Pharm. Soc, Jap., 72, 400 (1952).

10) H.J. Vogel and D.M. Bonner, J. Biol. Chem., 218, 97
(1956).
} 
As a preliminary test, the authors investigated the utilization of acyl methionines by Escherichia coli. Namely, several methionine requiring mutants of Escherichia coli were cultured on the basal medium with the addition of acyl methionines. As a result of this growth study, these acyl derivatives were found to be utilized by the mutants, which may be interpreted that the added acyl methionines were utilized for growth after being deacylated by the bacteria. In order to ascertain the presence of acylase activity, cell extracts of the parent strain of Escherichia coli $K-12$ and of the mutant strain were studied and both extracts were found to be capable of hydrolizing acyl methionines. Furthermore, comparative study of the extracts of acetonedried cells of Escherichia coli and Aerobacter aerogenes revealed that there was no difference of hydrolytic activity between both bacteria. Hence, to obtain information on the characteristics of this acylase system in Escherichiae, the following properties, i. e., hydrolytic activity towards various acyl amino acids, optimal $\mathrm{pH}$, influence of metal ions and other enzymic properties were investigated by employing the alcohol-fractionated extracts obtained from acetone-dried cells of Escherichia ocil $K-12$ as the enzyme preparation.

\section{EXPERIMENTAL}

Compounds Used The preparation of the amino acid derivatives was reported in the previous papers by the authors.

Organism The organisms used were Aerobacter aerogenes, Escherichia coli $K-12$ and its methionine requiring mutants such as $58-161, Y-40$ and $K i-1023$; these were originated from the culture collection of the Department of Genetics, School of Medicine, Osaka University. The mutant strain Ki-1023 was isolated by Kisumi, one of the authors, with UV radiation and subsequent penicillin screening ${ }^{11}$.

Growth Study and Preliminary Tests The basal medium used for the growth study was the same as that employed by Davis ${ }^{12)}$. To the test tube containing autoclaved basal medium, sterile-filtered solu-

11) J. Lederberg, Methods in Medical Research, 3, 5 (1950).

12) B.D. Davis, J. Am. Chem. Sor., 70, 4267 (1948). tion of acetyl-, chloroacetyl-, glycyl-methionines and methionine were added in respective concentrations. One-loop of the appropriate microorganism which had been grown in a complete agar medium at $37^{\circ}$ for 20 hours, was suspended in saline and then centrifuged. One drop of the saline suspension of the washed cells (ca $10^{7}$ cells $/ \mathrm{ml}$ ), was used to inoculate each tube. Incubation was carried out at $37^{\circ}$ for 20 hours, and growth was estimated by reading turbidities on a Beckmann model spectrophotometer at $515 \mathrm{~m} \mu$. The result of this growth study is summarized in Table I. As shown in the Table, acetylmethionine was available

TABLE I

Utilization OF METhIONINE DERIVATIVES BY METHIONINELESS MUTANTS OF ESCHERICHIA COLI

Methionine derivs.

\begin{tabular}{|c|c|c|c|}
\hline \multirow{2}{*}{$\begin{array}{l}\text { Concen- } \\
\text { tration } \\
\text { (M) }\end{array}$} & \multicolumn{3}{|c|}{$E$. coli* } \\
\hline & $\begin{array}{l}58- \\
161\end{array}$ & & $\begin{array}{l}K \\
10\end{array}$ \\
\hline- & & & \\
\hline $10^{-3}$ & & & \\
\hline $10^{-4}$ & & & \\
\hline $10^{-5}$ & & & \\
\hline $10^{-3}$ & & & \\
\hline $5 \times 10$ & & & \\
\hline $10^{-4}$ & 59 & & \\
\hline $10^{-3}$ & 0 & & \\
\hline $5 \times 10^{-4}$ & 59 & & \\
\hline $10^{-4}$ & 60 & 62 & \\
\hline $10^{-3}$ & 00 & 99 & \\
\hline$\times 10^{-4}$ & 84 & 99 & \\
\hline $10^{-4}$ & 82 & 99 & \\
\hline
\end{tabular}

none

L-Methionine

"l

"

Acetyl-L-methionine

"l

"I

Chloroacetyl-L-methionine

"I

"I

Glycyl-L-methionine

"I

"

$10^{-4} \quad 82 \quad 99 \quad 61$

* Expressed in terms of transmittance.

for the growth of all mutants tested and the same growth was observed as in the case of methionine. Although chloroacetyl derivative was also fully available at lower levels, somewhat inferior growth was recognized at higher concentrations. Except for strain $\mathrm{Ki}$-1023, replacability of glycylmethionine for methionine was very poor, especially in case of strain $Y-40$ which could not grow with this glycyl derivative. It is worthy of note that although any difference of extent of utilization was not observed among the mutants tested in case of acyl derivatives, apparent difference between the mutant strains was observed in the case of the glycyl derivative.

The above experiment infers that the acyl methionines were utilized after deacylation by an enzyme present in methionineless mutants of Escherichia coli. So, 
with the cell extracts of methionine requiring mutant $K-1023$ and of its parent strain, hydrolytic activity to acyl- and glycyl-methionines was investigated. Namely, both strains were grown on a complete agar medium at $37^{\circ}$ for 20 hours. The cells were harvested with M/30 phosphate buffer ( $\mathrm{pH} 7.0$ ) by centrifugation, suspended in the phosphate buffer, and collected again. Four grams of the wet cells were ground with quartz-sand and extracted with $40 \mathrm{mI}$ of the phosphate buffer. The supernatant obtained by centrifugation was used as the extracts.

As shown in Table II, although both parent and mutant strains were capable of hydrolizing acyl

Table II

Hydrolysis OF METHIONINE DERIVATIVES BY CELl ExTRacts of ESCHERICHIA COLI

Extent of hydrolysis (\%)

Methionine derivs.

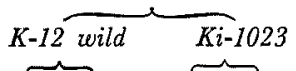

4 hrs. 24 hrs. 4 hrs. 24 hrs.

$\begin{array}{lrrrr}\text { Acetyl-DL-methionine* } & 21 & 71 & 12 & 51 \\ \text { Chloroacetyl-L-methionine } & 9 & 47 & 5 & 30 \\ \text { Glycyl-L-methionine } & 100 & & 100 & \end{array}$

The incubation mixture contained $1 \mathrm{ml}$ of $0.025 \mathrm{M}$ substrate solution $(0.05 \mathrm{M}$ in the case of acetyl.DL-methionine), $1 \mathrm{ml}$ of phosphate buffer and $1 \mathrm{ml}$ of the extracts. The reaction mixture was incubated at $37^{\circ}$ and $\mathrm{pH}$ 7.0. The liberated amino acid was measured by the colorimetric ninhydrin method.

* Extent of hydrolysis is expressed for the susceptible isomer of the substrate.

methionines, the activity of the former was found to be somewhat higher than the latter.

In order to compare the acylase activity of the above Escherichia coli and Aerobacter aerogenes, both strains were cultivated in the same way as described above, and the harvested cells were acetone-dried. The dried cells were extracted with $M / 30$ phosphate buffer (pH 7.0) and centrifuged. The extracts were made up to a concentration corresponding to $5 \mathrm{mg}$ of dried cells per $\mathrm{ml}$. With these extracts, hydrolysis of various acyl amino acids was carried out at $\mathrm{pH}$ 7.0. The results, listed in Table III, indicate that although acyl derivatives of alanine, leucine, methionine and phenylalanine were hydrolyzed, the cleavage of the derivatives of glutamic acid, lysine, tryptophan and tyrosine did not occur under the conditions employed by the authors. Throughout the experiment almost no difference between both Eschericheae was observed, and it was also evident that the hydrolytic activity to glycylmethionine, a peptidase activity, was

TABLE III

Hydrolysis of ACYL AMINo ACIDS BY CELl-FreE EXTRACTS OF ESCHERICHIA COLI AND AEROBACTER AEROGENES

Substrate

Clac-Alanine

Clac-Leucine

Ac-Methionine

Clac- " "

Gly- "I

Ac-Glutamic acid

Clac- "

$\varepsilon-\mathrm{Bz}-\boldsymbol{\alpha}-\mathrm{Ac}-\mathrm{Ly}$ sine

$\varepsilon-\mathrm{Bz}-\alpha$-Clac- "

Ac-Tryptophan

Clac- "

Clac-Phenylalanine Clac-Tyrosine
Extent of hydrolysis (\%)

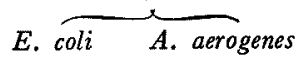

$9 \quad 11$

41

$56 \quad 49$

$20 \quad 20$

$82 \quad 36$

$0 \quad 0$

21

$0 \quad 0$

11

$0 \quad 0$

$0 \quad 0$

$19 \quad 2$

$2^{\circ} \quad 2$

Ac: Acetyl, Clac: chloroacetyl, Gly : glycyl

The incubation mixture contained $1 \mathrm{ml}$ of $0.025 \mathrm{M}$ substrate solution $(0.05 \mathrm{M}$ for tacemic compound), $1 \mathrm{ml}$ of the extracts and $1 \mathrm{ml}$ of $\mathrm{M} / 15$ phosphate buffer. The reaction mixture was incubated at $37^{\circ}$ and $\mathrm{pH} 7.0$ for 24 hours. The liberated amino acid was determined by the colorimetric ninhydrin method, and extent of reaction expressed as per cent hydrolysis of the susceptible substrate.

* Ten-times diluted extracts was employed.

higher than the acylase activity in these crude extracts.

Enzyme Preparation For the purpose to investigate the enzyme properties of acylase activity in Eschericheae, of which the occurrence of activity was ascertained through the experiments described above, a wild strain of Escherichia coli $K-12$ was chosen for enzyme preparation. The cells grown on a complete medium were harvested, washed, and acetone-dried in the usual manner. The dried cells were extracted with 20-times of $\mathrm{M} / 30$ phosphate buffer ( $\mathrm{pH} 7.0$ ) and centrifuged. The supernatant solution was treated with alcohol ( $50 \%$ by volume) under chilling, the precipitate formed was removed by centrifugation and cold alcohol (70\% by volume) was added to the supernatant solution. A precipitate formed, which contained $90 \%$ of the total activity of the crude extracts, was dissolved in phosphate buffer at $\mathrm{pH} 7.0$. The resulting solution was employed as the stock enzyme solution, $1 \mathrm{ml}$ of which corresponds to $25 \mathrm{mg}$ of dried cells, and the activity assayed under the standard conditions described below by the use of acetyl-DL-methionine at $\mathrm{pH} \mathrm{6.5,} \mathrm{was}$ $6.6 \mu \mathrm{M} / \mathrm{hr} / \mathrm{N} \mathrm{mg}$ protein. The stock solution kept by 
freezing, was thawed and properly diluted before it was used for the enzyme reaction.

Standard Enzyme Reaction Enzyme reaction was carried out by incubating digests composed of $1 \mathrm{ml}$ of $0.025 \mathrm{M}$ substrate solution $(0.05 \mathrm{M}$ for racemic compounds), $1 \mathrm{ml}$ of enzyme solution and $1 \mathrm{ml}$ of $\mathrm{M} / 15$ phosphate buffer (at appropriate $\mathrm{pH}$, described in Table VI) at $37^{\circ}$ for an appropriate period. Liberated amino acids during the incubation were measured by the colorimetric ninhydrin method, and expressed by per cent hydrolysis of the susceptible L-isomer.

For example, effect of enzyme concentration (varying dilutions of the stock enzyme solution) on the rate of hydrolysis under the standard conditions with acetylDL-methionine as the substrate, is shown in Fig. 1. The result indicated the extent of hydrolysis was proportional to enzyme concentration.

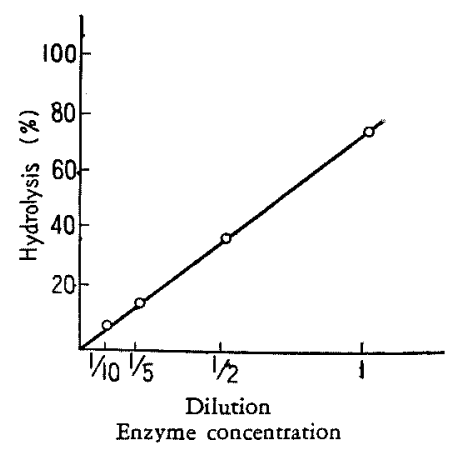

FIG. 1. Effect of Enzyme Concentration of Reaction Rate.

The mixture containing enzyme solutions of varying dilu. tion and acetyl-pL-methionine was incubated at $\mathrm{pH} 6.5$ for 3 hours under standard conditions.

Storage and Stabilization of the Enzyme Solution As for the above described enzyme preparation from Escherichia coli which lost activity during storage, stabilization of the enzyme solution was studied. Namely, glutathione, ascorbic acid, sodium sulfide and sodium cyanide were added as possible preservatives to the enzyme solution, and their activities were assayed after storage. Effect of storage by freezing was also investigated for comparison. As shown in Table IV, the stock enzyme lost about a half of its initial activity during the storage in a refrigerator at 5 for two weeks. The addition of ascorbic acid and sodium cyanide showed no preserving effect and sodium sulfide had ill-effect. Although the addition of glutathione was effective to prevent decrease of activity, it
TABLE IV

EFFECT of STORAGE TO THE ENZyMe ACTIVITY

\begin{tabular}{llrrrr}
$\begin{array}{c}\text { Exp. } \\
\text { No. }\end{array}$ & Additions & $\begin{array}{c}\text { Concentra* } \\
\text { tion* }\end{array}$ & \multicolumn{2}{c}{$\begin{array}{c}\text { Enzyme Ac- } \\
\text { tivity (days) }\end{array}$} \\
& & & 3 & 7 & 14 \\
1 & None & & 75 & 70 & 47 \\
2 & None (freezing) & & 94 & 91 & 88 \\
3 & Glutathione & $2 \times 10^{-4} \mathrm{M}$ & 85 & 79 & 52 \\
4 & Glutathione & $10^{-3} \mathrm{M}$ & 88 & 83 & 81 \\
5 & Ascorbic Acid & $5 \times 10^{-3} \mathrm{M}$ & 72 & 65 & \\
6 & $\mathrm{Na}_{2} \mathrm{~S}$ & $10^{-3} \mathrm{M}$ & 15 & & \\
7 & $\mathrm{NaCN}$ & 11 & 69 & 60 &
\end{tabular}

Enzyme assay was carried out under standard conditions for 2 hours with acetyl-DL-methionine. For the expression of enzyme activity, the activity of fresh preparation was taken as 100 and per cent activity was employed.

* Concentration in the enzyme solution.

resulted in an undesirable increase of the enzyme blank in case of assay. So the most favorable step was to store the enzyme solution in the frozen state.

As for the restoration of the diminished activity, the addition of cobalt chloride and glutathion to the fresh and deteriorated enzymes, was studied. The results, shown in Table $\mathrm{V}$, revealed that the addition of cobalt and the simultaneous addition of glutathione with cobalt, stimulated the fresh enzyme activity in the same order of magnitude, while glutathione employed alone showed no stimulatory effect. In the case of stored enzyme, which activity had decreased to one-third of the initial activity, cobalt ion stimulated the remaining

TABLE $\mathrm{V}$

RESTORATION OF THE DIMINISHED ENZYME ACTIVITY

$\begin{array}{clrr}\begin{array}{llr}\text { Exp. } \\ \text { No. }\end{array} & \text { Addition (concentration)* } & \overbrace{0} \text { Storage (days) } \\ 1 & \text { None } & 100 & 36 \\ 2 & \mathrm{Co}^{++}\left(2 \times 10^{-4} \mathrm{M}\right) & 309 & 130 \\ 3 & \text { Glutathione }\left(10^{-3} \mathrm{M}\right) & 85 & 28 \\ 4 & \mathrm{Co}^{++}\left(2 \times 10^{-4} \mathrm{M}\right)+\text { glutathione } & 330 & 264 \\ & \quad\left(10^{-3} \mathrm{M}\right) & & \\ 5 & \mathrm{Co}^{++}\left(2 \times 10^{-4} \mathrm{M}\right)+\text { glutathione } & 319 & 267\end{array}$

Enzyme assay was carried out under the same conditions as described in Table IV.

* Final concentration in reaction mixture.

activity and reactivation of diminished activity could not be observed, although, the simultaneous addition of cobalt ion and glutathione was evidently effective for restoration.

Effect of $\mathbf{p H}$ In a previous paper ${ }^{6)}$, the authors 
TABLE VI

OPTIMAL pH FOR THE HYDROLYSIS OF ACYL AMINo ACIDS

$\begin{array}{lcc}\text { Acyl derivs. } & \text { Acetyl } & \text { Chloroacetyl } \\ \text { Alanine } & 6.2 & 5.9 \\ \text { Leucine } & 6.4 & 5.9 \\ \text { Methionine } & 6.5 & 5.6 \\ \text { Glutamic Acid } & - & - \\ \text { Aspartic Acid } & 6.7 & 7.3 \\ \text { e-Benzoyllysine } & - & 5.1 \\ \text { Tryptophan } & - & - \\ \text { Phenylalanine } & - & 5.1 \\ \text { Tyrosine } & & -\end{array}$

The reaction was carried out under standard conditions for 6 hours.

observed that the optimum $\mathrm{pH}$ towards acetyl and chloroacetyl derivatives somewhat differed in the case of fungal acylase preparation. So, the effect of $\mathrm{pH}$ on the hydrolytic rate of various acyl amino acids by the preparation from Escherichia coli was studied and the optimal $\mathrm{pH}$ was determined. The results obtained are summarized in Table VI. Although the optimum $\mathrm{pH}$ for chloroacetyl derivatives seemed to be only slightly on the acidic-side than that of acetyl derivatives, no appreciable difference of optimal $\mathrm{pH}$ for both acyl derivatives as found in mold preparation could be detected. Among the chloroacetyl derivatives tested, optimal $\mathrm{pH}$ for that of aspartic acid was exceptionally on the alkaline-side. While, on the chloroacetyl derivatives of phenylalanine and $\varepsilon$-benzoyllysine, which the optimal $\mathrm{pH}$ existed on the acidic-side the experiments were repeated with Michaelis acetate buffer from which it was ascertained that there was no shift of the optimal $\mathrm{pH}$ in both buffers. Hydrolysis of the acyl derivatives of tryptophan and glutamic acid, acetyl derivatives of $\epsilon$-benzoyllysine and phenylalanine, and chloroacetyltyrosine was not detected after prolonged incubation at $\mathrm{pH} 6.5$.

Besides the acyl amino acids listed in the Table, optimum $\mathrm{pH}$ for glycylmethionine was also studied and it was estimated as 7.8 .

Susceptibility of Acyl Amino Acids In the preliminary test, the extent of hydrolysis of typical acyl amino acids by the cell extracts of Escherichia coli and Aerobacter aerogenes at $\mathrm{pH} 7.0$ was investigated. In this chapter, the susceptibility of the various acyl amino acids towards the bacterial acylase preparation was studied in the initial rates of hydrolysis at their respective optimal $\mathrm{pH}$. The results obtained are summarized in Table VII, in which the rates of hydrolysis were converted to relative susceptibility taking that of acetyl methionine as 100 for the convenience of interpreting the results.

Acyl derivatives of monoaminomonocarboxylic acids such as alanine, leucine and methionine were hydrolyzed, especially, methionine derivatives were found to be most susceptible to the preparation. Further, hydrolytic activity to glycylmethionine, a peptidase

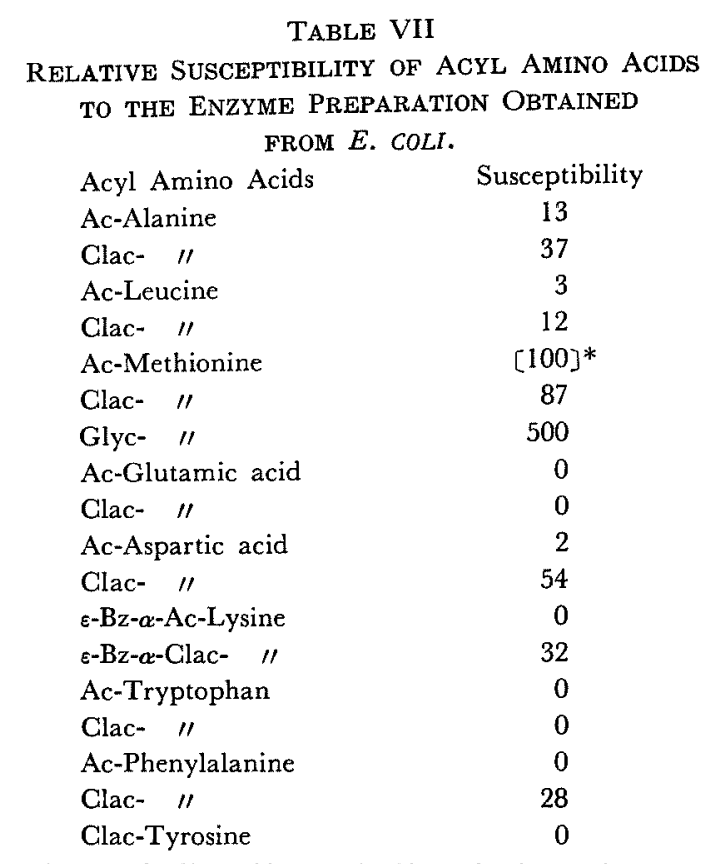

Ac: acetyl, Clac: chloroacetyl, Glyc: glycyl, Bz: benzoyl

The enzyme reaction was carried out under the standard conditions for 6 hours.

* $6.6 \mu \mathrm{M} / \mathrm{hr} . / \mathrm{N} \mathrm{mg}$ of protein

action, appeared to be higher than the acylase activity. On the derivatives of monoaminodicarboxylic acids, although acyl glutamic acids were not hydrolyzed, chloroacetyl aspartic acid was found to be quite susceptible. While, among the lysine derivatives tested, only chloroacetyl derivative was hydrolyzed.

Generally, the acyl aromatic amino acids were less susceptible to this bacterial acylase preparation. Namely, except in case of chloroacetylphenylalanine, hydrolysis of the other acyl aromatic amino acids such as acetyltryptophan, acetylphenylalanine and chloroacetyltyrosine was not recognized under the conditions employed by the authors.

As in cases of acylase preparations obtained from other sources such as mold acylase and hog kidney 
TABLE VIII

EFFECT OF METALS AND INHibitors on The ENZyMe ACTIVIEY

$\begin{array}{lcccc}\text { Additions } & \begin{array}{c}\text { Acetyl- } \\ \text { methionine }\end{array} & \begin{array}{c}\text { Chloroacetyl- } \\ \text { methionine }\end{array} & \begin{array}{c}\text { Chloroacetyl- } \\ \text { phenylalanine }\end{array} & \begin{array}{c}\text { Glycyl- } \\ \text { methionine }\end{array} \\ \text { None } & 100 & 100 & 100 & 100 \\ \mathrm{Cu} & 0 & 2 & 0 & 74 \\ \mathrm{Mg} & 88 & 88 & 47 & 86 \\ \mathrm{Ca} & 90 & 96 & 73 & 138 \\ \mathrm{Zn} & 6 & 23 & 65 & 78 \\ \mathrm{Mn} & 110 & 108 & 82 & 1100 \\ \mathrm{Fe} & 103 & 107 & 120 & 128 \\ \mathrm{Co} & 209 & 203 & 297 & 3800 \\ \mathrm{Ni} & 11 & 39 & 53 & 97 \\ \text { EDTA } & 27 & 34 & 7 & 48 \\ \text { PCMB } & 6 & 22 & 3 & 7\end{array}$

The assay was carried out under standard conditions for 3 hours. Final concentration of the additions was $10^{-3} \mathrm{M}$. The activity of the respective substrate without addition was taken as 100 . Metal chlorides were employed as metal ions in these experiments.

acylase, it was also observed in this bacterial preparation that chloroacetyl derivatives were more susceptible than acetyl derivatives. It is, however, of interest to note that exceptionally acetylmethionine was readily hydrolyzed than the chloroacetyl derivative.

Effect of Metals and Inhibitors In order to study the effect of metals and inhibitors, acetyl-, chloroacetyl-methionines, and chloroacetylphenylalanine were employed as the substrates. Various metal ions, ethylenediaminetetraacetate and p-chloromecuribenzoate were added at the enzyme assay and their activities were compared. Besides the above mentioned acyl amino acids, effect to the hydrolysis of glycylmethionine was also studied for comparison.

The results, shown in Table VIII, revealed that the effect towards the all acyl amino acids tested were almost the same. Namely, stimulation of acylase activity was observed with cobalt ion. Though salts of magnesium, calcium, manganese, and iron, at the concentrations tested, affected the reaction slightly; however, salts of copper, zinc and nickel acted inhibitory.

In the case of glycylmethionine, not only cobalt but manganese also stimulated the hydrolytic activity, and the order of mgnitude of activation with these ions was much higher than that of acylase activity. While, the inhibitory effect of salts of copper, zinc and nickel appeared to a far lesser extent.

Marked inhibition by metal binder, ethylenediaminetetraacetic acid (EDTA), and by the sulfhydryl reagent, $p$-chloromercuribenzoate (PCMB) were observed in all the substrates tested.
Along with the above experiment, stimulation by cobalt ion was evident, so the influence of the concentration of the ion was investigated by employing acetyl and glycyl derivatives of methionine as the substrates. Under the conditions employed, optimal concentration was found to be at $10^{-3} \mathrm{M}$, or $10^{-4} \mathrm{M}$, and a three fold activation in acylase activity and more than fortyfold stimulation of peptidase activity were observed as shown in Fig. 2.

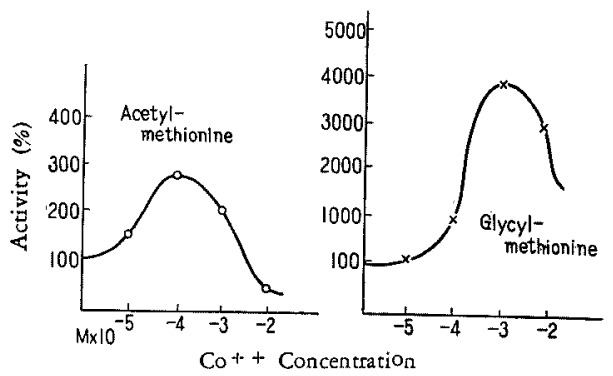

FIG. 2. Effect of Concentration of Cobalt on the Enzymatic Hydrolysis of Acetyl Methionine and Glycyl Methionine.

Experiments were carried out under standard conditions with the presence of varied concentrations of cobalt chloride for 3 hours.

Effect of Temperature For the purpose of studying the effect of temperature to the enzyme reaction, the extent of hydrolysis of acetyl-, chloroacetyl-, glycylmethionines and chloroacetyl aspartic acid as respective optimal $\mathrm{pH}$ and varied temperature was determined and is represented in Fig. 3. Maximal rates of hy- 

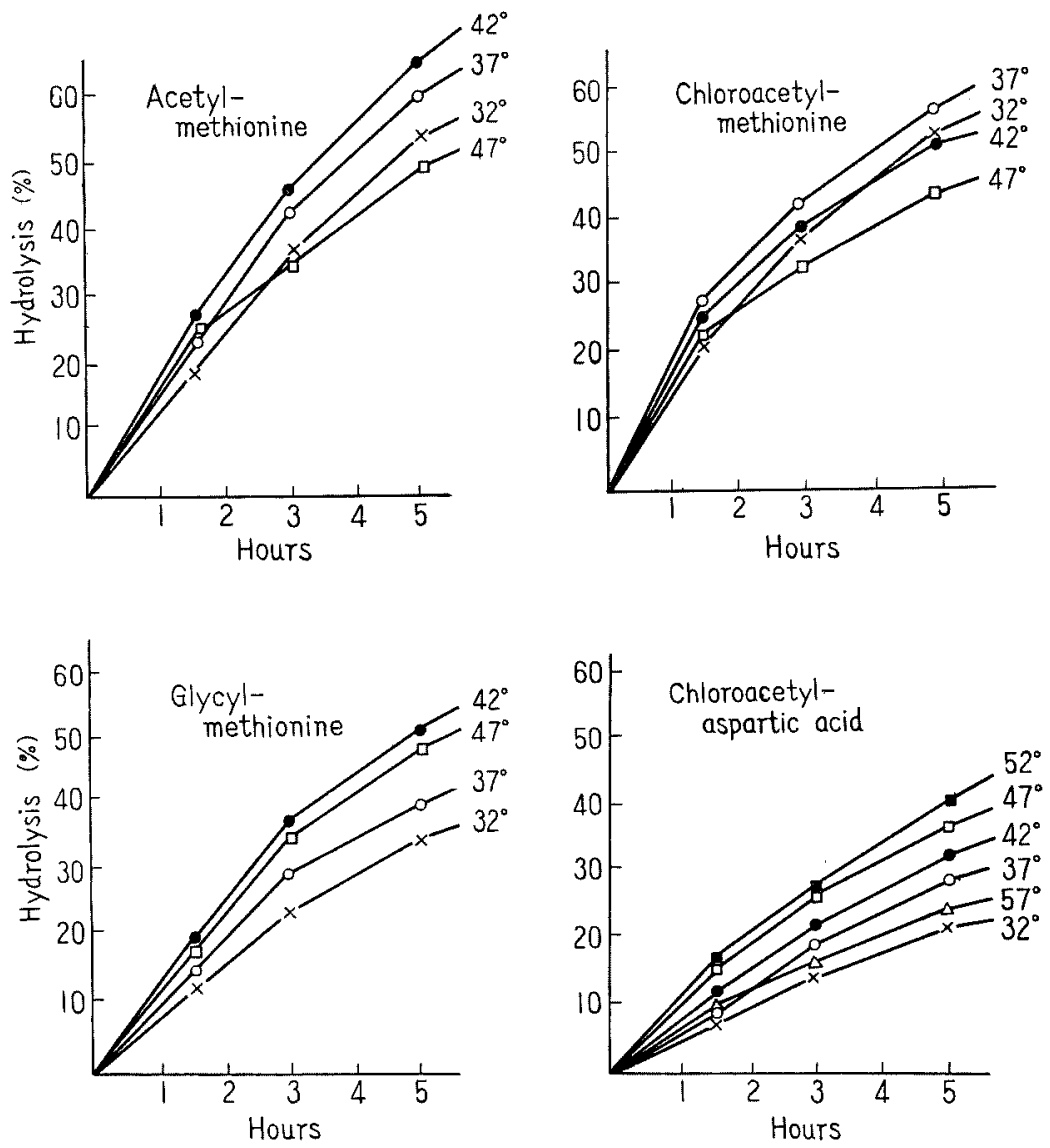

FIG. 3. Effect of Time and Temperature on the Hydrolysis by the Enzyme Preparation from $E$. coli.

The employed $\mathrm{pH}$ for the hydrolysis of acetyl-, chloroacetyl-, glycyl-methionines and chloroacetyl aspartic acid were $6.5,5.5,7.7$ and 7.3 , respectively.

drolysis were observed at $37^{\circ}$ for chloroacetylmethionine and at $42^{\circ}$ for acetyl, glycyl-methionines. While, the optimum temperature for the hydrolysis of chloroacetylaspartic acid was the highest, i.e., it was found to be at $52^{\circ}$.

Optical Specificity Since some of the bacterial enzymes had been known to act on the D-amino acid derivatives, optical specificity of this acylase preparation from Escherichia coli was investigated. The enzymatic reaction employing $0.025 \mathrm{M}$ acetyl-L-methionine and $0.05 \mathrm{M}$ acetyl-DL-methionine, as the substrate was simultaneously carried out under the standard conditions. As indicated in Fig. 4, in either cases, the extent of reaction stopped at the cleavage of $25 \mathrm{~mm}$ of the substrate, that is, 100\% hydrolysis of L-formsubstrate and 50\% hydrolysis of racemic substrate. This result shows that the bacterial acylase preparation is optically specific and it acts asymmetrically on the L-form of acyl amino acid and not on the D-isomer. Whereas, it seemed that the presence of $\mathrm{D}$-isomer did not appreciablly affect the rate of hydrolysis of the acyl-L-amino acid within the sensitivity of the method employed. 


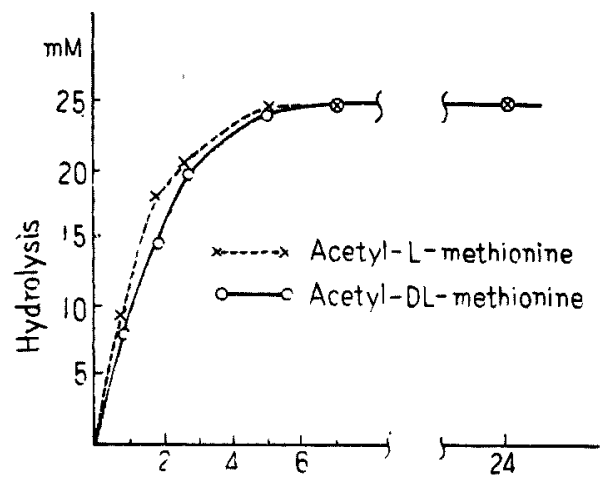

FIG. 4. Hydrolysis of acetyl derivatives of $\mathrm{L}-$ and DL-methionines by the enzyme preparation from $E$. coli. The enz ymatic reaction employing $0.025 \mathrm{M}$ acetyl-L-methionine and $0.05 \mathrm{M}$ acetyl-DL-methionine was carried out at $\mathrm{pH} 6.5$ under standard conditions. Fxtent of hydrolysis in the figure is expressed as mM of the liberated amino acid.

\section{DISCUSSION}

Through the growth study of mutant strains and the enzymatic study of cell extracts, the occurrence of acylase activity in Eschericheae has been ascertained.

Subsequent studies on the characteristics of the bacterial acylase preparation from Escherichia coli have revealed that although peptidase activity is high, acylase activity of this preparation is lower and the variety of the susceptible acyl amino acids is also less than that of previously studied fungal acylase preparation, which is capable to readily hydrolyze acyl derivatives of various types of aliphatic and aromatic amino acids. Especially, hydrolytic activity towards acyl aromatic amino acids appears to be very low, chloroacetylphenylalanine is the only susceptible one among those tested under the conditions employed by the authors.

The present study also reveals that this preparation resembles other acylase preparations such as hog kidney and mold acylases in several features. These features include the specific stimulation by cobalt ion. The inhibition observed by the addition of ethylenediaminetetraacetic acid and p-chloromarcuribenzoate indicates that metal ion and sulfhydryl group play an important role in this enzyme action. Furthermore, optical specificity is also similar to other acylases, that is, L-form of the acyl amino acids is hydrolized selectively.

On the studies of optimum $\mathrm{pH}$ and temperature, somewhat exceptional behavior of chloroacetylaspartic acid was noted. Although the decision as to whether or not the difference observed is due to the presence of one or more specific acylases in this enzyme preparation, has to wait until the enzyme is obtained in further purified state.

In this study, attempts were not made to separate the aclyase activity from the peptidase action, although, the influence of metal ions towards both activities somewhat differed. For instance, peptidase activity is markedly stimulated not only by cobalt ion as in the case of acylase activity, but also by manganese ion. Also in another case, the inhibitory effect of copper and other metals observed in acylase activity, was not so evident.

As described above, some enzymatic properties of acylase activity in Escherichiae have been disclosed. The authors are intending to continue studies on the occurrence and enzymatic characteristics of acylase activity in various organisms in order to clarify biological significancc of the presence of acylase activity.

Acknowledgements. The authors are grateful to Prof. H. Mitsuda of Kyoto University, and Dr. M. Fujisawa of this Laboratory for their helpful advice and encouragement. They were also indebted to Prof. H. Kikkawa of Osaka University for generously supplying the microorganisms used in this work. 